\title{
Sociodemographic Status of Propofol and Dexmedetomidine as an Agent of Conscious Sedation in Patients Undergoing Tympanoplasty
}

Md. Abdur Rahim ${ }^{1 *}$, Mir Mohammad Rifat Chowdhury ${ }^{2}$, Rahnuma Tasnim ${ }^{3}$, Md. Arif Uddin ${ }^{4}$, Md. Abdul Karim ${ }^{5}$, AKM Akhtaruzzaman ${ }^{6}$, Iqbal Hossain Chowdhury ${ }^{7}$, S. M. Rashidul Hasan ${ }^{8}$

\footnotetext{
${ }^{1}$ Registrar, Cardiac Anaesthesia, National Heart Foundation and Research Institute, Dhaka, Bangladesh

${ }^{2}$ Junior Consultant, Cardiac Anaesthesia, National Heart Foundation and Research Institute, Dhaka, Bangladesh

${ }^{3}$ Medical officer, Department of Anaesthesia, Analgesia and Intensive Care Medicine, Bangabandhu Sheikh Mujib Medical University, Dhaka, Bangladesh

${ }^{4} J u n i o r$ Consultant (Current Charge), 100 Bed Burn Unit, Dhaka Medical College Hospital, Dhaka, Bangladesh

${ }^{5}$ Consultant, Orthopaedic and Truma Surgeon, Dr. Azmal Hospital Ltd, Dhaka, Bangladesh

${ }^{6}$ Professor, Department of Anaesthesia, Analgesia and Intensive Care Medicine, Bangabandhu Sheikh Mujib Medical University, Dhaka, Bangladesh

${ }^{7}$ Associate Professor, Department of Anaesthesia, Analgesia and Intensive Care Medicine, Bangabandhu Sheikh Mujib Medical University, Dhaka, Bangladesh

${ }^{8}$ Registrar, Cardiac Anaesthesia, National Heart Foundation and Research Institute, Dhaka, Bangladesh
}

DOI: $10.36347 /$ sjams.2020.v08i09.014

| Received: 05.09.2020 | Accepted: 13.09.2020 | Published: 17.09.2020

*Corresponding author: Md. Abdur Rahim

Abstract

Original Research Article

Objective: In this study our main goal is to assess sociodemographic characteristics of propofol and dexmedetomidine as an agent of conscious sedation in patients undergoing tympanoplasty. Method: This Randomised prospective clinical trial study was carried out with the patients who underwent tympanoplasty conducted at ENT operation theatre in BSMMU, Dhaka according to inclusion \& exclusion criteria from February 2016 to February 2018. ASA I-II patients aged (18-45) years undergoing tympanoplasty were enrolled. Patients were randomized as Group I and Group II by computer-gerenated randomization where there was 30 patients in each group $(n=30)$. Results: Both groups were almost similar in respect to age, weight, height, BMI. Mean age of the patient group-I was $30.93 \pm 7.11$ and $29.03 \pm$ 7.36 in group-II and among them maximum age was 50 years and minimum age was 19 years in group-I and 44,14 years in group-II. Mean weight of the patient group-I was $58.43 \pm 6.88$ and $57.50 \pm 5.52$ group-II and among them maximum weight was $72 \mathrm{~kg}$ and minimum weight was $45 \mathrm{~kg}$ in group-I and 67,49 years in group-II. Mean height of the patient group-I was $1.60 \pm 0.06$ and $1.59 \pm 0.06$ group-II and among them maximum height was 1.73 and minimum height was 1.49 in group-I and 1.79,1.49 meter in group-II.Mean BMI of the patient group-I was $22.72 \pm$ 2.60 and $22.52 \pm 2.18$ group-II. Demographic data between the two groups were not statistically significant. During the study, a computer-generated randomization table was used to allocate the patients into 2 equal groups, 30 in each where Group I received dexmedetomidine and Group II received propofol. Observations were made during perioperative period for conscious sedation effectiveness on haemodynamics SBP, MAP, DBP, HR, SpO2 on different time intervals, surgical field bleeding status, patient satisfaction, surgeon satisfaction, intraoperative rescue sedation, intraoperative rescue analgesics, postoperative rescue analgesics, time to achieve target Ramsay sedation scale (RSS) after induction, intra and postoperative pain intensity level, and adverse effects . Demographic data and different parameter were described as mean with standard deviation in different tables and graphical presentation on different types of charts. Conclusion: From our results we can conclude that, conscious sedation with dexmedetomidine with local anaesthetic lignocaine infiltration provides better outcome of conscious sedation in terms of patient's satisfaction, surgeon's satisfaction, reduce per operative surgical site bleeding for patients undergoing tympanoplasty.

Keywords: Propofol, Dexmedetomidine, haemodynamics. Tympanoplasty.

Copyright @ 2020: This is an open-access article distributed under the terms of the Creative Commons Attribution license which permits unrestricted use, distribution, and reproduction in any medium for non-commercial use (NonCommercial, or CC-BY-NC) provided the original author and source are credited.

\section{INTRODUCTION}

There are various types of surgeries done in ears including external, middle and internal ear either individually or simultaneously. This procedure done under different types of anaesthetic technique like general anaesthesia, local infiltration, local infiltration with sedation, regional blocks and or combination all above procedures. Each of technique has its own advantages and disadvantages. 
Using local anaesthesia only comparison to general anaesthesia in terms of patient recovery, patient turnover, and avoidance of intubation and elimination of possibility of laryngotracheal complicaiton is as well as removal of cardiovascular, respiratory, renal, and neurological complications. Local anaesthesia also reduce intraoperative bleeding and helps perioperative hearing assessment, vertigo detection required during surgery. It also prevents potentially lengthy and disturtive emergence from general anaesthesia.

Propofol is a newer drug has been used for conscious sedation have narrow therapeutic index, risk of progression to deep sedation. It has no analgesic effect and must be used with adequate pain relief. Profopol causes hypotension, apnoea required intervention during conscious sedation [1]. It also causes hypoxia, vomiting, deep sedation, caughing, agitation, airway obstruction, desaturation, higher recall [2].

Therefore, suitable drugs and adequate doses for sedation have been debated and variety of drugs used around the world used and consequently search for appropiate newer drugs continues. The alpha 2 agonist dexmedetomidine now a day's widely used for its sedative analgesic and sympatholytic properties in the perioperative and critical care. It was approved by FDA 1999 for used as sedative agents [3]. It has shorter halflife and eight fold greater sensitivity and selectivity for the receptor than clonidine [4]. It also attenuates the stress response to surgery, provides opioid sparing effect, stable haemodynamics [5]. It shows that intra operaitve administration of dexmedetomidine maintain haemodynamic stability. It prevents post-operative nausea, vomiting, shivering and potential benefits of cardio, neuro and renal protection [6]. It can be used in perioperative period as an analgesic adjunct. Lower heart rate and mean arterial pressure provides better operative field for microscopic surgery [7]. It decreases bleeding when bloodless surgical field required. Dexmedetomidine used significantly less tramadol in FESS and septoplasty [8]. It is better drug for conscious sedation with better haemodynamic stability; reduce analgesic requirements fentanyl about 44\% [9].

Significantly higher rates of effective sedation in dexmedetomidine compared with midazolam [10]. It has calmer, cooperative, higher satisfaction score without compromising airway. It is safe to use in impending respiratory failure [11]. Dexmedetomidine has been used for various surgical procedures, preserved muscle tone and spontaneous ventilation and awaken by external stimulus [12]. EEG study demonstrated sedative effects of dexmedetomidine mimics second stage of non REM sleep [13]. In USA dexmedetomidine approved for sedation of nonintubated patient or during surgical procedure. A Conchrane review 2009 examined benefits of alpha 2 agonist in obtunding the perioperative stress induced sympathetic activity [14]. In CNS dexmedetomidine stimulates brainstem reduce heart rate and decrease blood pressure [15]. It has selective alpha 2 agonist with properties of analgesia, sympatholysis and can titrate sedation without respiratory depression. It reduces opioid requirements and stress response to surgery ensuring a stable haemodynamics [16]. It is increasingly used for various surgical procedures. The use of dexmedetomidine in other ENT surgeries like FESS, septoplasty, thyroplasty under conscious sedation has also documented [17]. It can be safely and effectively used for surgeries under conscious sedation. At low or moderate doses with slow rates of infusion of dexmedetomidine alpha 2 agonist effects are observed but no alpha 1 effect. It has been used as sedatives and analgesic as single agent in many procedures [18].

In our country few articles published on dexmedetomidine shows that dexmedetomidine infusion reduces the NT-Pro BNP level has better cardiac outcome for patients undergoing ORIF for fracture shaft of femur. But no such study yet did on tympanoplasty at Bangladesh [19]. We assume that conscious sedation with dexmedetomidine may be a better alternative to other sedative drugs for patient undergoing tympanoplasty.

\section{OBJECTIVE}

General objective

Assess sociodemographic characteristics of propofol and dexmedetomidine as an agent of conscious sedation in patients undergoing tympanoplasty.

\section{Specific objective}

- To compare intra operative haemodynamics. (SBP, DBP, MAP, SPO2, HR).

- To compare operative field bleeding by bleeding scale.

- To compare time to achieve adequate sedation by Ramsay sedation scale.

- To compare time of full recovery from sedation by modified Aldrete score.

\section{Methodology \\ Study type}

- This was an Randomised prospective clinical trial.

\section{Study place and period}

This study was carried out with the patients who underwent tympanoplasty conducted at ENT operation theatre in BSMMU, Dhaka according to inclusion \& exclusion criteria from February 2016 to February 2018

\section{Sampling method}

- The sample was collected by computer generated random sampling. 


\section{Study population}

- Total 30 patients were included in this study.

\section{Selection Criteria \\ Inclusion criteria}

- All Patients (both male and female) underwent tympanoplasty.

- Aged between 18-45 years of age.

- ASA physical status I and II

\section{Exclusion criteria}

- Patient (both male \& female) refused to be included in the study.

- COPD, asthma, Cardiac, renal, hepatic dysfunction or disease.

- History of difficult intubation.

- Coagulopathy or coagulation disorder.

- Obesity (20\% of ideal body weight).

- History of drug allergy.

- Patients requiring endotracheal intubation.

- Sleep apnoea.

\section{Procedure of data collectio}

This randomized clinical trial took place at BSMMU in ENT operation theatre under Department of Anaesthesia, Anaelgesia and Intensive care medicine after approval by Institutional Review Board (IRB). Patients were randomized as Group I and Group II by computer-gerenated randomization where there was 30 patients in each group $(n=30)$. Patients were interviewed for detailed medical and drug history and underwent a physical examination before the surgery to verify whether fulfill inclusions criteria. Before the surgery, patients were instructed clearly about anaesthetic technique, NRS pain scale.

The group I received dexmedetomidine and group II received propofol. After taking the patient on the operation table, a monitoring device was attached and baseline haemodynamics (SBP, DBP, MAP, SpO2, HR) were noted. An intravenous cannula was inserted for giving intravenous fluids and drugs. All patients were monitored with an automated noninvasive blood pressure device, pulse oximetry, and an electrocardiogram. Drugs were prepared and two $50 \mathrm{ml}$ syringes were labeled as loading and maintainence syringe for each patient.

Patients in Group I were get injection dexmedetomidine loading dose $1 \mu \mathrm{gm} / \mathrm{kg}$ over 10 minute followed by continuous infusion $0.4 \mu \mathrm{gm} / \mathrm{kg} / \mathrm{hr}$. Patients in the Group II were get injection propofol loading dose $75 \mu \mathrm{gm} / \mathrm{kg}$ intravenously over 10 minute than $50 \mu \mathrm{gm} / \mathrm{kg} / \mathrm{min}$ continuous infusion was started.

Patients were observed for the depth of sedation throughout the period of surgery and sedation both intraoperatively and postoperatively. Light sedation was assumed from the observation of haemodynamics, somatic (movement, eye opening or grimacing) or autonomic (lacrimation, sweating) changes. Light sedation symptoms were treated by administering a bolus of fentanyl $(0.5 \mu \mathrm{gm} / \mathrm{kg})$ followed by titration of doses of propofol and dexmedetomidine. Hypotension is treated with intravenous fluids and titrating the infusion rate of drugs. Vasopressor drugs are administered if hypotension persists. Bradycardia is treated with anticholinergic drugs. At the end of the surgery, infusion is discontinued. Surgeons were asked to grade their satisfaction with sedation technique after the end of surgery. Patients were asked to grade their overall satisfaction with the procedure during transfer to ward or postoperative ward from the recovery ward. Any intra and postoperative interventions were also recorded. Drug trial registration is under processing. Applied to clinical trial .gov. PRS registration and password was created.

\section{Statistical Analysis}

All relevant collected data was compiled on a master data sheet first. Then organized. Statistical analyses were carried out by using the Statistical Package for Social Sciences version 16.0 for Windows (SPSS Inc., Chicago, Illinois, USA). The mean values were calculated for continuous variables. The quantitative observations will be indicated by frequencies and percentages. Chi-Square test was used to analyze the categorical variables like sex, ASA status and surgical satisfaction, patient satisfaction which was shown with cross tabulation. Un paired t-test was used for continuous variables like systolic blood pressure (SBP), diastolic blood pressure (DBP), mean arterial pressure (MAP), heart rate (HR), percent saturation of oxygen $(\mathrm{SpO} 2)$ at different interval. Unpaired t-test was also be used for age, weight, height, duration of surgery. $P$ values $<0.05$ was considered as statistically significant.

\section{RESULTS}

\section{Demographic data}

Both groups were almost similar in respect to age, weight, height, BMI. Mean age of the patient group-I was $30.93 \pm 7.11$ and $29.03 \pm 7.36$ in groupII and among them maximum age was 50 years and minimum age was 19 years in group-I and 44, 14 years in group-II.

Mean weight of the patient group-I was 58.43 \pm 6.88 and $57.50 \pm 5.52$ group-II and among them maximum weight was $72 \mathrm{~kg}$ and minimum weight was $45 \mathrm{~kg}$ in group-I and 67,49 years in group-II. Mean height of the patient group-I was $1.60 \pm 0.06$ and $1.59 \pm$ 0.06 group-II and among them maximum height was 1.73 and minimum height was 1.49 in group-I and 1.79, 1.49 meter in group-II. Mean BMI of the patient group-I was $22.72 \pm 2.60$ and $22.52 \pm 2.18$ group-II. Demographic data between the two groups were not statistically significant. 
Table-I: Demographic data and clinical data $(n=30$ each group)

\begin{tabular}{|l|c|c|c|}
\hline \multicolumn{1}{|c|}{ Parameter } & \multicolumn{2}{c|}{ Groups } & P value \\
\hline (n = 30 each group) & Group I & Group II & \\
\hline Age & $30.93 \pm 7.11$ & $29.03 \pm 7.36$ & ${ }^{\mathrm{a}} 0.31^{\mathrm{ns}}$ \\
\hline Range & 19,45 & 14,44 & \\
\hline Weight & $58.43 \pm 6.88$ & $57.50 \pm 5.52$ & ${ }^{\mathrm{a}} 0.56^{\mathrm{ns}}$ \\
\hline Range & 45,72 & 49,67 & \\
\hline Height & $1.60 \pm 0.06$ & $1.59 \pm 0.06$ & ${ }^{\mathrm{a}} 0.72^{\mathrm{ns}}$ \\
\hline Range & $1.49,1.73$ & $1.49,1.79$ & \\
\hline BMI & $22.72 \pm 2.60$ & $22.52 \pm 2.18$ & ${ }^{\mathrm{a}} 0.75^{\mathrm{ns}}$ \\
\hline ASA grade & & & \\
\hline I & $28(93.3 \%)$ & $26(86.7 \%)$ & ${ }^{\mathrm{b}} 0.38^{\mathrm{ns}}$ \\
\hline II & $2(6.7 \%)$ & $4(13.3 \%)$ & \\
\hline Marital status & & & \\
\hline Married & $24(80 \%)$ & $17(56.7 \%)$ & ${ }^{\mathrm{b}} 0.09^{\mathrm{ns}}$ \\
\hline Unmarried & $6(20 \%)$ & $13(43.3 \%)$ & \\
\hline
\end{tabular}

Significant ${ }^{\mathrm{s}}$, non-significant ${ }^{\mathrm{n}}$

Values were expressed as number and percentages.

${ }^{b} \mathrm{p}$ was derived from chi square test, ${ }^{\mathrm{a}} \mathrm{p}$ was derived from unpaired $\mathrm{t}$ test.

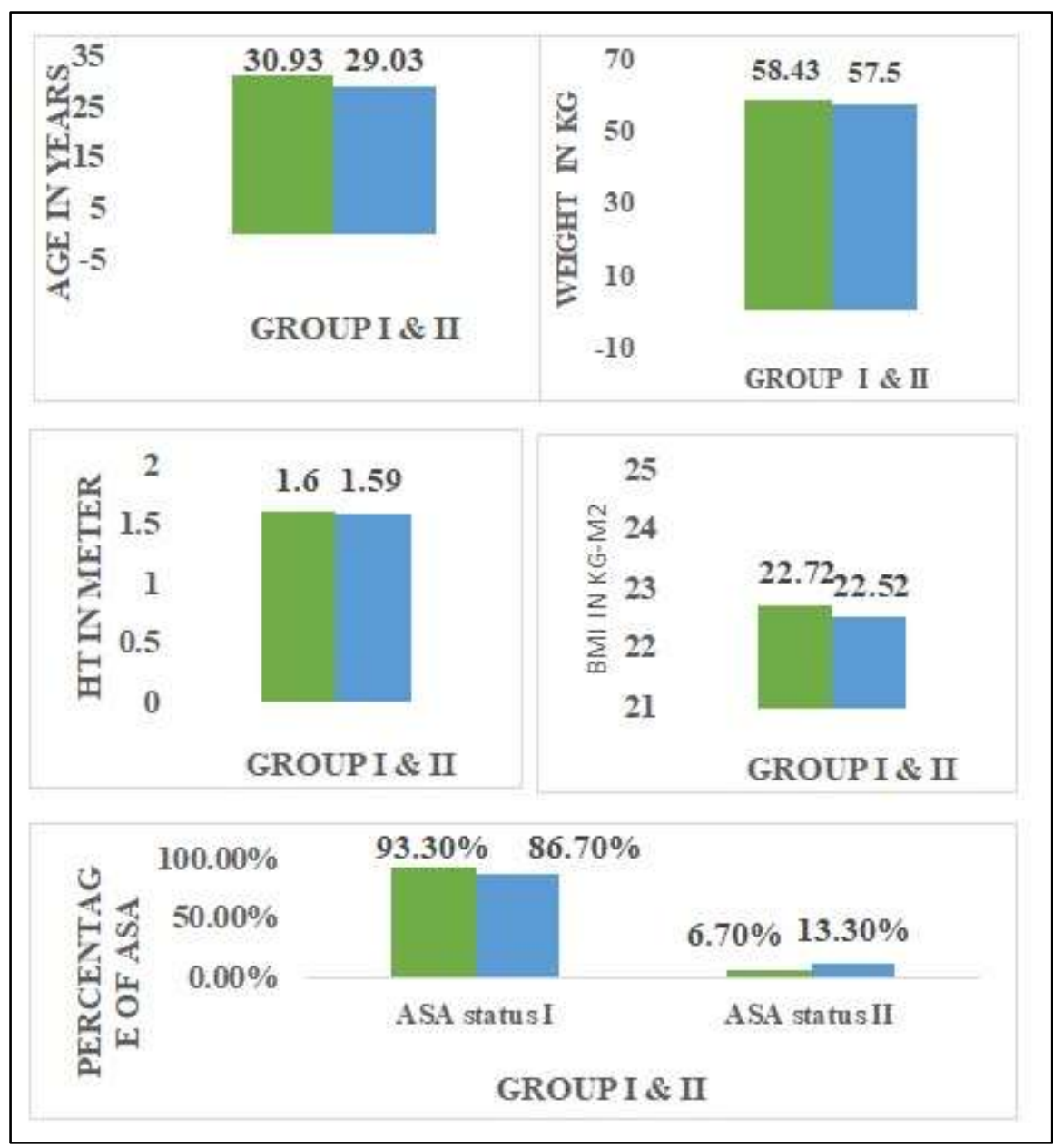

Fig-I: Bar chart showing comparison of Demographic data

Perioperative haemodynamics

\section{Mean arterial blood pressure}

Base line mean \pm SD value of MAP in Group I was $84.91 \pm 3.49 \mathrm{~mm}$ of $\mathrm{Hg}$. DBP during different evaluation period varied from $82.87 \pm 2.91 \mathrm{~mm}$ of $\mathrm{Hg}$ to $83.35 \pm 3.17 \mathrm{~mm}$ of $\mathrm{Hg}$. On the other hand base line
MAP of Group II was $83.12 \pm 4.20 \mathrm{~mm}$ of $\mathrm{Hg}$ and during different evaluation period ranged from $82.77 \pm$ $4.12 \mathrm{~mm}$ of $\mathrm{Hg}$ to $85.42 \pm 4.32 \mathrm{~mm}$ of $\mathrm{Hg}$. The changes were similar most of the observation and showed no significant differences between groups. 


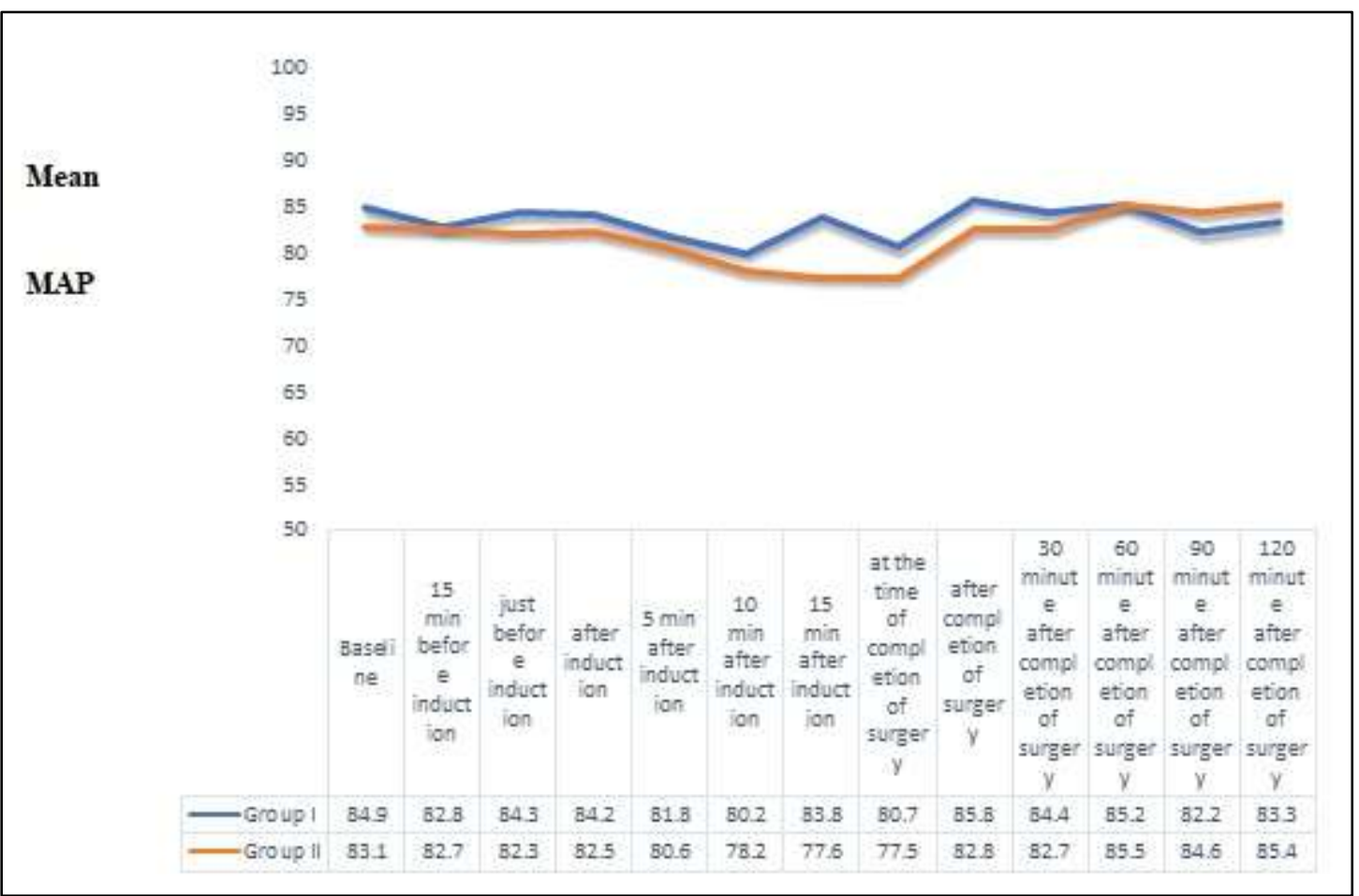

Fig-II: Line diagram showing comparison of MAPof two groups in different time intervals throughout the perioperative period. (Mean)

\section{Time to achieve target RSS}

Time to achieve target RSS after induction. Among group I, 24(80\%) patient achieves target sedation $($ RSS $=3)$ within $(8-10)$ minutes and $3(10 \%)$ within (5-8) minutes and $3(10 \%)$ patients' needs more than 10 minutes to achieve target RSS .On the contrary among group II, 25(83.3\%) patient achieves target sedation (RSS = 3) within (1-5) minutes and 4 (13.3\%)within (5-8) minutes and 1 (3.3\%) patients' needs more than 10 minutes to achieve target RSS. Study revealed Group II found statistically significant $(\mathrm{P}<0.05)$.

Table-II: Ramsay sedation score $(\mathrm{n}=\mathbf{3 0}$ each group)

\begin{tabular}{|c|c|c|c|c|c|}
\hline Groups & $(\mathbf{1 - 5})$ minute & $(\mathbf{5 - 8})$ minute & $(\mathbf{8 - 1 0})$ minute & Above10 minute & ${ }^{\mathbf{b}}$ pvalue \\
\hline Group I & $0 \%$ & $10 \%(3)$ & $80 \%(24)$ & $10 \%(3)$ & $0.01^{\mathrm{s}}$ \\
\hline Group II & $83.3 \%(25)$ & $13.3 \%(4)$ & $0 \%$ & $3.3 \%(1)$ & \\
\hline
\end{tabular}

Values were expressed as number and percentages.

${ }_{\mathrm{b}}^{\mathrm{p}}$ was derived from chi square test.

\section{Intraoperative pain intensity}

Intraoperative pain intensity score at different grade in intraoperative period. Among group I, 23 (76.7\%) patients have no pain, $4(13.3 \%)$ have mild pain $3(10 \%)$ have moderate pain with the anaesthesia technique. On the contrary $21(70 \%)$ have no pain, 3 $(10 \%)$ have mild pain and 6(20\%) have moderate pain with the anaesthesia technique in group II respectively. Study revealed Group II found statistically significant $(\mathrm{P}<0.05)$.

Table-III: Pain intensity ( $\mathrm{n}=\mathbf{3 0}$ each group)

\begin{tabular}{|c|c|c|c|c|c|c|}
\hline Parameters & Groups & No pain & Mild pain & $\begin{array}{l}\text { Moderate } \\
\text { pain }\end{array}$ & Severe pain & ${ }^{b}$ pvalue \\
\hline \multirow{2}{*}{$\begin{array}{c}\text { Intraoperative } \\
\text { period }\end{array}$} & Group I & $76.7 \%(23)$ & $13.3 \%(4)$ & $10 \%(3)$ & $0 \%$ & \multirow[b]{2}{*}{$0.04^{\mathrm{s}}$} \\
\hline & GroupII & $70 \%(21)$ & $10 \%(3)$ & $20 \%(6)$ & $0 \%$ & \\
\hline \multirow{2}{*}{$\begin{array}{l}\text { Postoperative } \\
\text { period }\end{array}$} & Group I & $63.3 \%(19)$ & $20 \%(6)$ & $16.6 \%(5)$ & $0 \%$ & \multirow[b]{2}{*}{$0.2^{\mathrm{ns}}$} \\
\hline & GroupII & $66.7 \%(20)$ & $30 \%(9)$ & $3.3 \%(1)$ & $0 \%$ & \\
\hline
\end{tabular}

Significant $^{\mathrm{s}}$, nonsignificant $^{\mathrm{ns}}$

Values were expressed as number and percentages.

${ }^{\mathrm{b}} \mathrm{p}$ was derived from chi square test. 


\section{Intra operative rescue sedation}

Rescue sedation during intraoperative period. Among group I, 25(83.3\%) needs no rescue sedation, and only $5(16.7 \%)$ patients required rescue sedation with the anaesthesia technique .On the contrary
$24(80 \%)$ patients not required rescue sedation and only $6(20 \%)$ patients required rescue sedation in group II respectively. Study revealed found statistically not significant.

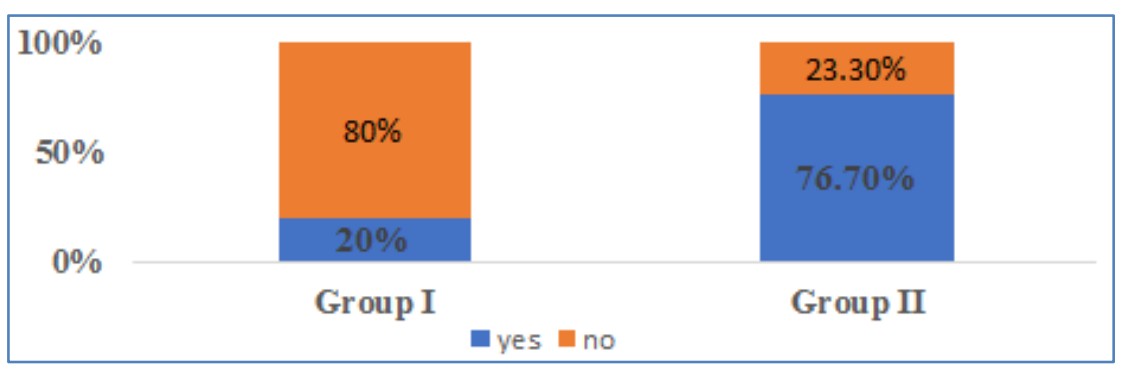

Fig-III: 100 percent Bar chart showing comparison of intraoperative rescue sedation

\section{Surgical field bleeding}

Surgical field assessed by bleeding score. Bleeding score is obtained during intraoperative period. Among group I, we found $19(66.7 \%)$ had score 0, which was considered no bleeding and the rest $11(33.3 \%)$ scored 1, was considered as mild bleeding with the anaesthesia technique required no aspiration. On the contrary only $9(30 \%)$ had score 0 , considered as no bleeding and the rest and most $17(56.7 \%)$ patients had score 1 , was considered as mild bleeding with the anesthesia technique required no aspiration and 1(3.3\%) had score 1 required aspiration, 2(6.7\%) had score 3 was considered mild bleeding required frequent aspiration and $1(3.3 \%)$ patient had score 4 was considered moderate bleeding in group II respectively. No group had scored 5 which were considered as severe bleeding. Study revealed Group I found statistically significant $(\mathrm{P}<0.05)$.

Table-IV: Bleeding score ( $\mathbf{n}=30$ each group)

\begin{tabular}{|c|c|c|c|c|c|c|c|}
\hline Groups & $\begin{array}{c}\text { No } \\
\text { bleeding }(0) \\
\end{array}$ & $\begin{array}{c}\text { Mild } \\
\text { bleeding }(1)\end{array}$ & $\begin{array}{c}\text { Mild } \\
\text { bleeding (2) }\end{array}$ & $\begin{array}{c}\text { Mild } \\
\text { bleeding (3) }\end{array}$ & $\begin{array}{c}\text { Moderate } \\
\text { bleeding (4) }\end{array}$ & $\begin{array}{c}\text { Severe } \\
\text { bleeding (5) }\end{array}$ & $\begin{array}{c}{ }^{\mathbf{b}} \mathbf{P} \\
\text { value } \\
\end{array}$ \\
\hline Group I & $66.7 \%(19)$ & $33.3 \%(11)$ & $0 \%$ & $0 \%$ & $0 \%$ & $0 \%$ & \multirow[b]{2}{*}{$0.04^{\mathrm{s}}$} \\
\hline Group II & $30 \%(9)$ & $56.7 \%(17)$ & $3.3 \%(1)$ & $6.7 \%(2)$ & $3.3 \%(1)$ & $0 \%$ & \\
\hline
\end{tabular}

\section{Patient satisfaction}

Patient satisfaction assessed by Likert scale. Among group I, we found 23(80\%) p had score 5, was considered very satisfied and $4(13.3 \%)$ patients scored 4, was considered as satisfied, 2 patients are neutral had score 3, and 1 (3.3\%) scored 2 was considered dissatisfied with the anaesthesia technique .
On the contrary only $5(16.7 \%)$ had score 5 , considered as very satisfied and rest and most $22(73.3 \%)$ had score 4 was considered as satisfied and $3(10 \%)$ patients were neutral had score 3 in group II No group had scored 1 which was considered as very dissatisfied. Study revealed Group I found statistically significant $(\mathrm{P}<0.05)$.

Table-V: Satisfaction score $(n=30$ each group)

\begin{tabular}{|c|l|c|c|c|c|c|c|}
\hline Parameters & Groups & $\begin{array}{c}\text { Very } \\
\text { dissatisfied }\end{array}$ & Dissatisfied & Neutral & Satisfied & $\begin{array}{c}\text { Very } \\
\text { satisfied }\end{array}$ & $\begin{array}{c}{ }^{\mathbf{b}} \mathbf{P} \\
\text { value }\end{array}$ \\
\hline \multirow{2}{*}{$\begin{array}{c}\text { Patient } \\
\text { satisfaction }\end{array}$} & Group I & $0 \%$ & $3.3 \%(1)$ & $6.7 \%(2)$ & $13.3 \%(4)$ & $80 \%(23)$ & \\
\cline { 2 - 7 } & GroupII & $0 \%$ & $0 \%$ & $10 \%(3)$ & $73.3 \%(22)$ & $16.7 \%(5)$ & $0.01^{\mathrm{s}}$ \\
\hline $\begin{array}{c}\text { Surgeon } \\
\text { satisfaction }\end{array}$ & Group I & $0 \%$ & $0 \%$ & $6.7 \%(2)$ & $3.3 \%(2)$ & $90 \%(26)$ & \\
\cline { 2 - 7 } 0 & GroupII & $0 \%$ & $0 \%$ & $13.3 \%(4)$ & $73.3 \%(22)$ & $13.3 \%(4)$ & $0.01^{\mathrm{s}}$ \\
\hline
\end{tabular}

Significant ${ }^{\mathrm{s}}$ non-significant ${ }^{\mathrm{n}}$

Values were expressed as number and percentages.

${ }^{b} \mathrm{p}$ was derived from chi square test.

\section{Aldrete score} significant.

Patient satisfaction, surgeon satisfaction, time of achievement of modified Aldrete score was statistically 
Table-VI: Aldrete score $(n=30$ each group)

\begin{tabular}{|c|c|c|c|c|c|}
\hline Groups & $\mathbf{( 1 - 5 )}$ minute & $\mathbf{( 5 - 8 )}$ minute & $\mathbf{( 8 - 1 0 )}$ minute & Above10 minute & ${ }^{\mathbf{b}}$ P value \\
\hline Group I & $96.7 \%(29)$ & $3.3 \%(1)$ & $0 \%$ & $0 \%$ & \multirow{2}{*}{$0.05^{\mathrm{ns}}$} \\
\hline Group II & $46.7 \%(14)$ & $53.3 \%(23)$ & $0 \%$ & $0 \%$ & \multirow{2}{*}{} \\
\cline { 1 - 5 }
\end{tabular}

Significant ${ }^{\mathrm{s}}$ non significant ${ }^{\mathrm{ns}}$

Values were expressed as number and percentages.

${ }^{\mathrm{b}} \mathrm{p}$ was derived from chi square test.

\section{DICUSSION}

Patients for tympanoplasty surgery were recruited into this prospective, randomized clinical trial study with the aim to assess sociodemographic characteristics of propofol and dexmedetomidine as an agent of conscious sedation.

In this study, it was observed that the mean age was $30.93 \pm 7.11$ years in group I and 29.03 \pm 7.36 years in group II, which were almost alike between two groups. Similarly, showed the mean age was $44.31 \pm 5.19$ years in group A and $46.10 \pm 5.58$ years in group B [20]. On the other hand, observed higher mean age in their study, where the found the mean age was $52.6 \pm 2.2$ years in group I and 53.0 \pm 1.9 years in group II. Similarly higher mean age also observed by [21]. The higher mean age may be due to geographical variations, racial, ethnic differences, genetic causes, different lifestyle, and increased life expectancy may have significant influence on disease.

In this present study, the mean weight was $58.43 \pm 6.88 \mathrm{~kg}$ in group I and $57.50 \pm 5.52 \mathrm{~kg}$ in group II, which was almost similar between two groups and it was not statistically significant. Our study in terms of mean weight mostly similar to [22].

In this current study, it was observed that, almost $93.3 \%$ patients in group I and $86.7 \%$ in group II had ASA Grade I which was almost same between two groups. The present study findings are closely resembled.

In our study perioperative haemodynamics was stable and it was not statistically significant may be due to patient was well hydrated in both groups and surgery time was short duration. Moreover dexmedetomidine have a direct effect at the postsynaptic vascular smooth muscle to cause vasoconstriction and this alpha 2 adrenoreceptor mediated inhibit ympathoinhibitory action of dexmedetomidine. It was observed that $80 \%$ of the patient in group I achieve target RSS within 8-10 minutes and in group II $83.3 \%$ patient within 1-5 minutes corresponds with the results was found by [23].

In this study, it was observed that intraoperative pain intensity score among group I, 23 $(76.7 \%)$ patients have no pain, $4(13.3 \%)$ have mild pain $3(10 \%)$ have moderate pain with the anaesthesia technique .On the contrary $21(70 \%)$ have no pain, 3 $(10 \%)$ have mild pain and $6(20 \%)$ have moderate pain with the anaesthesia technique in group II respectively.
Study revealed Group II found statistically significant $(\mathrm{P}<0.05)$. The mean VAS value was lower in dexmedetomidine group compared to midazolam as the target VAS value were found significantly higher VAS in midazolam group compared to propofol. Our study also corresponds to and it was statistically significant.

It was observed that Among group I, $25(83.3 \%)$ needs no rescue sedation, and only 5 (16.7 $\%)$ patients required rescue sedation with the anaesthesia technique .On the contrary $24(80 \%)$ patients not required rescue sedation and only $6(20 \%)$ patients required rescue sedation in group II respectively. The total number of rescue doses of sedatives was lesser in dexmedetomidine group consistent with the findings of [7].

In this present study, Rescue analgesia during intraoperative period. Among group I, we found $23(76.7 \%)$ patients' needs no rescue analgesia, and only $7(23.3 \%)$ patients required rescue analgesia with the anaesthesia technique. On the contrary 10(33.3\%) patients required rescue analgesics and 20(66.7\%) patients not required rescue analgesics in group II respectively. Study revealed Group II found statistically significant $(\mathrm{P}<0.05)$ consistent with the result of.

In this current study, it was observed surgeon satisfaction assessed Among group I, 26(90\%) patients had score 5, was considered very satisfied and On the contrary only $4(13.3 \%)$ patients had score 5, considered as very satisfied in group II. demonstrated significantly better patient and surgeon satisfaction in dexmedetomidine group. Our studies also correspond with who also found better patient and surgeon satisfaction. Similarly the surgeon satisfaction was higher with dexmedetomidine as it provides calm and cooperative patient and better surgical field [24].

In our study it was observed that bleeding score was less in dexmedetomidine group and provides better surgical condition in comparison to propofol. Among group I, we found $19(66.7 \%)$ had score 0 on the contrary only $9(30 \%)$ had score 0 in group II. Clonidine reduces blood loss and provide better surgical condition in comparison to midazolam Clonidine and Dexmedetomidine both are found effective in reducing bleeding in ENT surgeries [25].

\section{CONCLUSION}

In conclusion this prospective randomization study demonstrated that compairing the 
dexmedetomidine and propofol for conscious sedation in tympanoplasty we found that dexmedetomidine have better satisfaction in both patient and surgeon, less bleeding score, less requirements of analgesics both intra operative and postoperative period. Haemodynamic parameters are unremarkable.

\section{REFERENCE}

1. Swanson ER, Seaberg DC, Mathias S. The use of propofol for sedation in the emergency department. Academic Emergency Medicine. 1996 Mar;3(3):234-8.

2. Skokan EG, Pribble C, Bassett KE, Nelson DS. Use of propofol sedation in a pediatric emergency department: a prospective study. Clinical pediatrics. $2001 \mathrm{Dec} ; 40(12): 663-71$.

3. Gerlach AT, Murphy CV, Dasta JF. An updated focused review of dexmedetomidine in adults. Annals of Pharmacotherapy. 2009 Dec;43(12):2064-74.

4. Yuan H, Chiang CY, Cheng J, Salzmann V, Yamashita YM. Anesthesia \&Analgesia. 2008; 106: 1715-21.

5. Arain SR, Ebert TJ. The efficacy, side effects, and recovery characteristics of dexmedetomidine versus propofol when used for intraoperative sedation. Anesthesia \& Analgesia. 2002 Aug 1;95(2):461-6.

6. Panzer O, Moitra V, Sladen RN. Pharmacology of sedative-analgesic agents: dexmedetomidine, remifentanil, ketamine, volatile anesthetics, and the role of peripheral mu antagonists. Anesthesiology clinics. 2011 Dec 1;29(4):587-605.

7. Delmade M, Parikh D. A prospective randomized double blind study to compare dexmedetomidine and midazolam in ear nose and throat surgery for monitored anesthesia care. Int $\mathrm{J}$ Res Med Sci. 2017;4:3159-63.

8. Karaaslan K, Yilmaz F, Gulcu N, Colak C, Sereflican M, Kocoglu H. Comparison of dexmedetomidine and midazolam for monitored anesthesia care combined with tramadol via patient-controlled analgesia in endoscopic nasal surgery: A prospective, randomized, double-blind, clinical study. Current therapeutic research. 2007 Mar 1;68(2):69-81.

9. Verma R, Gupta R, Bhatia VK, Bogra J, Agarwal SP. Dexmedetomidine and propofol for monitored anesthesia care in the middle ear surgery. Indian Journal of Otology. 2014 Apr 1;20(2):70.

10. Takimoto K, Ueda T, Shimamoto F, Kojima Y, Fujinaga Y, Kashiwa A, Yamauchi H, Matsuyama K, Toyonaga T, Yoshikawa T. Sedation with dexmedetomidine hydrochloride during endoscopic submucosal dissection of gastric cancer. Digestive Endoscopy. 2011 Apr;23(2):176-81.

11. Elhakim M, Abdelhamid D, Abdelfattach $H$, Magdy H, Elsayed A, Elshafei M. Effect of epidural dexmedetomidine on intraoperative awareness and post-operative pain after one-lung ventilation. Acta Anaesthesiologica Scandinavica. $2010 \mathrm{Jul} ; 54(6): 703-9$.

12. Ortega MR, Jambrina CC, Vallhonrat IL, Simón IF. Indications of dexmedetomidine in the current sedoanalgesia trends in the critical patient. Medicina Intensiva (English Edition). 2014 Jan $1 ; 38(1): 41-8$.

13. Huupponen E, Maksimow A, Lapinlampi P, Särkelä M, Saastamoinen A, Snapir A, Scheinin H, Scheinin M, Meriläinen P, HIMANEN SL, Jääskeläinen S. Electroencephalogram spindle activity during dexmedetomidine sedation and physiological sleep. Acta Anaesthesiologica Scandinavica. 2008 Feb;52(2):289-94.

14. Wijeysundera DN, Bender JS, Beattie WS. Alpha-2 adrenergic agonists for the prevention of cardiac complications among patients undergoing surgery. Cochrane database of systematic reviews. 2009(4).

15. Nelson LE, Lu J, Guo T, Saper CB, Franks NP, Maze M. The $\alpha 2$-adrenoceptor agonist dexmedetomidine converges on an endogenous sleep-promoting pathway to exert its sedative effects. Anesthesiology: The Journal of the American Society of Anesthesiologists. 2003 Feb $1 ; 98(2): 428-36$

16. Arain SR, Ebert TJ. The efficacy, side effects, and recovery characteristics of dexmedetomidine versus propofol when used for intraoperative sedation. Anesthesia \& Analgesia. 2002 Aug 1;95(2):461-6.

17. Dogan R, Erbek S, Gonencer HH, Erbek HS, Isbilen C, Arslan G. Comparison of local anaesthesia with dexmedetomidine sedation and general anaesthesia during septoplasty. European Journal of Anaesthesiology (EJA). 2010 Nov 1;27(11):560-964.

18. Demiraran Y, Korkut E, Tamer A, Yorulmaz I, Kocaman B, Sezen G, Akcan Y. The comparison of dexmedetomidine and midazolam used for sedation of patients during upper endoscopy: A prospective, randomized study. Canadian journal of gastroenterology. 2007 Jan;21.

19. Mirkheshti A, Memary E, Shafiee H, Dahi M. Effect of dexmedetomidine infusion on $\mathrm{N}$-terminal pro-B-type natriuretic peptide level in patients with femoral shaft fractures under general anesthesia. Bangladesh Journal of Pharmacology. 2016 Oct 1;11(4):765-70.

20. Nithipanich P, Mingsaun A, Marom S. The effect of pre-anesthetic administration of dexmedetomidine on postoperative pain and morphine consumption in patient receiving abdominal hysterectomy. The Thai Journal of Anesthesiology. 2016 Jun 30;42(2):96-105.

21. Ren C, Chi M, Zhang Y, Zhang Z, Qi F, Liu Z. Dexmedetomidine in postoperative analgesia in patients undergoing hysterectomy: a CONSORTprospective, randomized, controlled trial. Medicine. 2015 Aug;94(32).

22. Nithipanich P, Mingsaun A, Marom S. The effect of pre-anesthetic administration of 
dexmedetomidine on postoperative pain and morphine consumption in patient receiving abdominal hysterectomy. The Thai Journal of Anesthesiology. 2016 Jun 30;42(2):96-105.

23. Elhakim M, Abdelhamid D, Abdelfattach $\mathrm{H}$, Magdy H, Elsayed A, Elshafei M. Effect of epidural dexmedetomidine on intraoperative awareness and post-operative pain after one-lung ventilation. Acta Anaesthesiologica Scandinavica. 2010 Jul;54(6):703-9.
24. Nallam SR, Chiruvella S, Reddy A. Monitored anaesthesia care-Comparison of nalbuphine/dexmedetomidine versus nalbuphine/propofol for middle ear surgeries: A double-blind randomised trial. Indian journal of anaesthesia. 2017 Jan;61(1):61.

25. Kumari I, Naithni U, Bedi V, Gupta S, Gupta R. Comparison of clonidine versus midazolam in monitored anesthesia care during ENT surgery-A prospective, double blind, randomized clinical study. Anaesthesia, Pain \& Intensive Care. 2019 Feb 3:157-4. 